\title{
Milk, White and Bitter Filled Chocolate Design with Antep Cheese and Pepper
}

\author{
Fatma Yaliniz \\ Gaziantep University, Faculty of Tourism, \\ Department of Gastronomy, 27310, Gaziantep, Turkey \\ Email: fatirem2016@gmail.com \\ https://orcid.org/0000-0002-2002-3037
}

\begin{abstract}
Chocolate, which is a global product that is consumed all over the world, and a new chocolate was designed by using the local products of Gaziantep, the city of Gastronomy, with Antep cheese and pepper. The aim of this study is to combine two local products of Gaziantep, a city of gastronomy, with a global product and to expand its consumption. Whether this product can be accepted or not is evaluated by 10 panelists who are experts in chocolate with a hedonic scale. In addition, it was evaluated by these 10 panelists with a hedonic scale every 15 days until the deterioration of various quality parameters of the product (general taste, general color, general smell, Antep cheese taste and smell, Antep pepper taste and smell, general taste of chocolates) started. Results obtained from panel analysis SPSS 15.0 Evaluation Version Release 15.0.0 (6 Sept. 2006) The ANOVA test evaluated the effect of time on quality parameters and the T-test's general taste and general taste of chocolate. As a result of the statistics, it has been concluded that the samples with white, milk and dark chocolate filled with Antep pepper are able to withstand intact at about $15^{\circ} \mathrm{C}$ for three months, that is, the quality parameters are independent of time ( $p>0.05)$ and are acceptable chocolate according to the T-test. As a result of the statistics, it has been concluded that the samples of Antep cheese-filled white, milk and dark chocolate can last for three months without deterioration, that is, the quality parameters are independent of time ( $\mathrm{p}>0.05$ ), but not an acceptable chocolate according to the T-test.
\end{abstract}

Keyword: Chocolate, Gaziantep, cheese, pepper, sensory, analysis

DOI: $10.7176 / \mathrm{JSTR} / 7-02-05$

\section{INTRODUCTION}

When the most general definition of chocolate is made, it is a food product produced using chocolate, cocoa products and sugar. It is prepared with the addition of chocolate, milk, dairy products, other food ingredients and allowed additives and flavors. The basic composition of chocolates includes cocoa dry matter, cocoa butter and sugar. As a result of researches for different palate tastes, consumer demands and increasing chocolate quality, different chocolates are produced today and production techniques are improving day by day. Chocolate is divided into three types as dark (black), milk and white chocolate according to its types.

Chocolate is consumed only for the flavor it gives today. Considering the numerous benefits of chocolate for human health, it will be beneficial for the health of future generations that all individuals of all ages of the society should definitely include chocolate in their daily diets. Dark chocolate should be preferred especially in chocolate consumption ( www.foofelphi.com).

\section{Filled Chocolates}

There is a soft filling material on the inside of the filled chocolate, the outer part of which is covered with milk, dark and white chocolate. Fruit marmalades such as blueberries, oranges, strawberries, apples, blackberries and cherries or ingredients such as caramel, nuts and ice cream are placed in the inside of the filled chocolate (www.dergipark.gov.tr) 


\section{Use of Local Flavors in Chocolate Production}

New benefits of Antep pepper, which are very valuable in terms of health, are emerging day by day. In recent years, the healing effects of pepper on cancer disease have been revealed. Besides, it increases appetite by increasing stomach secretion. It is good for nerves, stomach and glands, facilitates digestion. It is diuretic; it is good for seasickness, rheumatism and muscle pain. It regulates blood circulation and pressure. It will be in our best interest not to miss such a useful vegetable from our table.

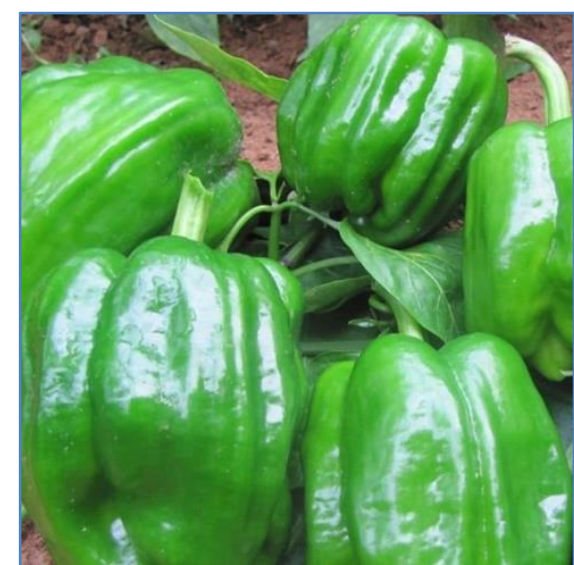

a) Fresh Antep Pepper

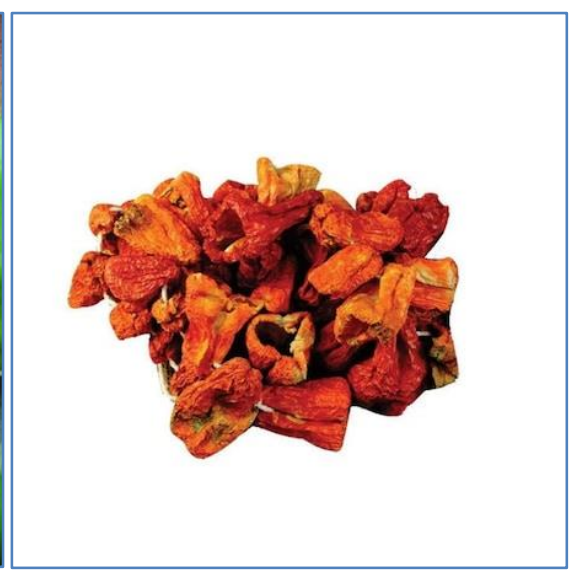

b) Dry Antep Pepper

Figure 1. Fresh and dry Antep pepper

Antep pepper is a vegetable that is widely used in food in this region. It is also a vegetable that is dried in the sun in summer and used in dry form in meals. Stuffed with dried pepper is the most common dish.

Antep Cheese is a type of cheese produced in Gaziantep and its region, usually made of sheep or goat milk. It is produced in the first spring months when sheep and goat milk are abundant. After the cheese sold without salt, it is pickled and consumed throughout the year.

This geographical indication was registered on 04.06.2018 to be protected as of 20.04.2017 within the scope of Article 41 of Industrial Property Law No. 6769. Antep cheese used in desserts and dishes in the Gaziantep region without salt; It is consumed abundantly at breakfasts in the Gazaintep region. Salty pickled cheeses are preferred for breakfast. Brine is made with plenty of salt to withstand the hot weather of Gaziantep. After the brine cheese is sliced in order to decrease and soften the salt, it is kept in hot water for a few minutes.

The fat rate changes according to the cheese production period. The most accepted are the most fatty cheeses. Oily cheeses are often found more towards the summer. The taste that the unsalted cheese leaves in the mouth during chewing and the sound it makes determines the quality of the cheese.

Antep Cheese is a local cheese produced in Gaziantep province and named after the same province. Antep Cheese is a type of cheese made from the milk of sheep and goats traditionally grazed in the pastures of Gaziantep province. Teleme is a boiled cheese that is produced and consumed as semi-hard, fresh (without brine) or ripened in brine. In production, only sheep or goat milk can be used, as well as $50 \%$ sheep and 50\% goat milk mixture can be used (www.kulturportali.gov.tr). 


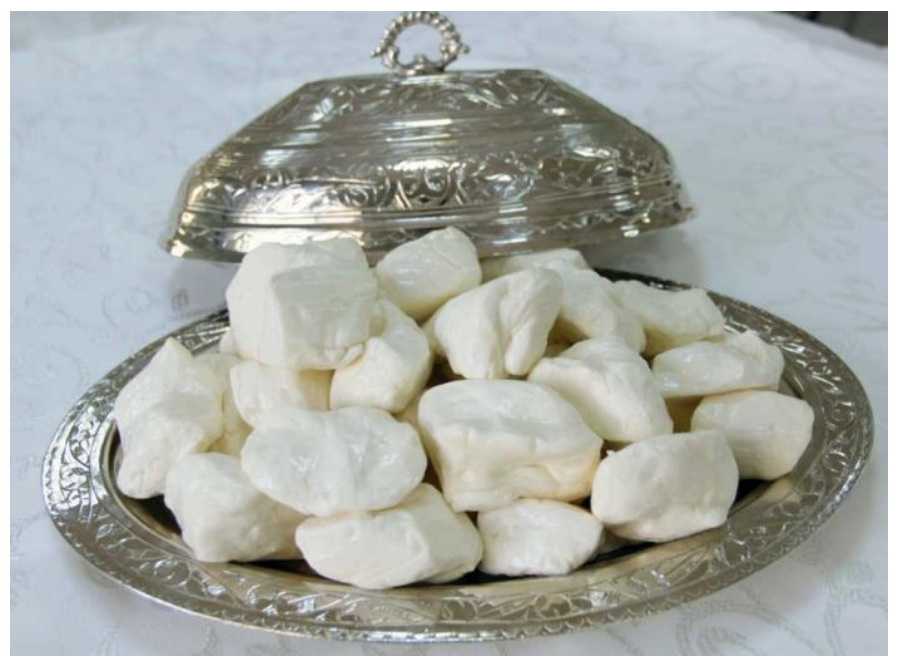

Figure 2. Fresh Antep cheese

\section{MATERIAL METHOD}

Material: The Antep cheese and dried pepper used in this study were taken from a local market in Antep. White, milk and dark brown chocolate and all the necessary materials were purchased from a supermarket in Antep.

\section{Preparation of Chocolate:}

The preparation of chocolate consists of nine steps.

1. Melting Chocolate Bar

2. Spilling Chocolate in Molds

3. Cooling

4. Doughing of more chocolate from the mold

5. Filling with Antep cheese mixture and Antep pepper mixture

6. Coating with chocolate

7. Chocolate cooling

8. Removing the chocolate from the mold

9. Packing and storage until sensory test.

\section{Antep Pepper Chocolate filling}

In this study $90 \mathrm{~g}$ cream, $30 \mathrm{~g}$ glucose, $10 \mathrm{~g}$ butter, $230 \mathrm{~g}$ white chocolate and $20 \mathrm{~g}$ dried ground Antep pepper were used. Cream and glucose were heated on the stove. Then white chocolate and butter were added and mixed until melted. The Antep pepper was added on it and mixed with a blender for a minute.

\section{Antep Cheese Chocolate filling}

In this study $200 \mathrm{~g}$ cream, $30 \mathrm{~g}$ glucose, $150 \mathrm{~g}$ unsalted Antep cheese, and $370 \mathrm{~g}$ white chocolate were used. Cream and glucose were heated on the stove. Then white chocolate and unsalted Antep cheese were added and mixed until melted and then mixed with a blender for a minute.

\section{SENSORY ANALYSES}

In this study, it is tried to determine whether the Antep pepper and cheese added by sensory analysis are acceptable in chocolate and also the shelf life of the chocolate obtained at 15-day intervals. In addition, it was tried to be informed about the general taste of chocolate. Six sensory analyzes were performed over a 3-month period. 10 participants participated in each analysis. Individuals evaluated the products independently during testing. The products were evaluated by giving different codes and which code belongs to which product is not known by the panelist. 9-hedonic scale sensory evaluation was used for evaluation of general acceptance of products, determination of storage durability and shelf-life, and acceptance of taste, color, odour criteria and Antep cheese and pepper odor and taste criteria. The analyzes were conducted with 10 semi-trained panelists. Before each analysis, the 47 I $P$ a g e www.iiste.org 
panelists were given about half an hour of training. The age range of the panelists was 25-35 years. Panel tests were performed between 11:00 a.m. and 11:30 a.m. at room temperature. Samples were given to panelists in the panel booth. Panelists were asked to evaluate the samples and mark the order of preference and the intensity of the sensory property (taste, color, smell, smell and taste of Antep cheese and pepper) on the given scale shown in Table 1. Panalists evaluated each sample after rinsing with water and eating a piece of bread and waiting for one minute. The results of sensory analysis were evaluated using variance analysis in SPSS program (15.0.0 Copyright (C) SPSS Inc. 2001).

Table 1. Hedonic scale for cookies.

\begin{tabular}{|l|l|c|c|}
\hline Liking Score & Panelist Hedonic Rating & $\begin{array}{c}\text { Sample I } \\
\text { (Chocolate with Antep } \\
\text { cheese filling }\end{array}$ & $\begin{array}{c}\text { Sample II } \\
\text { (Chocolate with Antep } \\
\text { pepper filling) }\end{array}$ \\
\hline 9 & Like extremely & & \\
\hline 8 & Like very much & & \\
\hline 7 & Like moderately & & \\
\hline 6 & Like slightly & & \\
\hline 5 & Neither like nor dislike & & \\
\hline 4 & Dislike slightly & & \\
\hline 3 & Dislike moderately & & \\
\hline 2 & Dislike very much & & \\
\hline 1 & Dislike extremely & & \\
\hline
\end{tabular}

\section{RESULT AND DISCUSSION}

The main purpose of this study is to combine the local Antep cheese and pepper, which belongs to the Gaziantep region, with a globally known and popular product such as chocolate, and turn this taste into a product that is consumed by everyone. Antep cheese is a cheese that is beneficial for health in its cheddar taste and structure. It is a type of cheese consumed by local people in Gaziantep, especially for breakfast. Apart from breakfast, it is also used frequently in various desserts and pastries. Antep pepper, on the other hand, is consumed fresh and dried in meals in this region. This pepper is used as pepper, especially in dry stuffed. In addition, the combination of sweet and bitterness is a new phenomenon emerging in the food industry. The unique taste and bitterness of Antep pepper is combined with the sweet taste of chocolate and the specific aroma of cocoa.

Chocolate filling material was prepared by combining Antep pepper and cheese with various substances such as milk cream and sugar (explained in detail in the method section). Unconched bitter, milk and white chocolate were conched, then poured into molds, filled with Antep pepper and cheese filling, and then covered with bitter, milk and white chocolate. Immediately after the chocolates were made, and at 15 days intervals, they were sensually evaluated by 10 semi-trained panelists. The results of sensory analysis test were evaluated by one way ANOVA test in SPSS. Tukey test was used for paired multiple comparisons. When the statistical results were examined, it was found that time $(\mathrm{p}>$ 0.05) was not an important parameter in general taste, color, odour, Antep cheese taste, Antep cheese odour and general like of bitter chocolate filled with Antep cheese. When Figure 3 was examined, it was observed that the general sensory properties (taste, color and odor) of the dark chocolate with Antep cheese did not change over time. It has been observed that at $18-20^{\circ} \mathrm{C}$, which is the storage temperature of the chocolate, this chocolate can remain unspoiled for approximately 75 days without adding any additives.

It is also understood from the sensory analysis test results that Antep cheese has a good taste compatibility with milk, bitter and white chocolate.

Similar results were obtained for milk and white chocolate filled with Antep cheese. Their graph values are not given. 


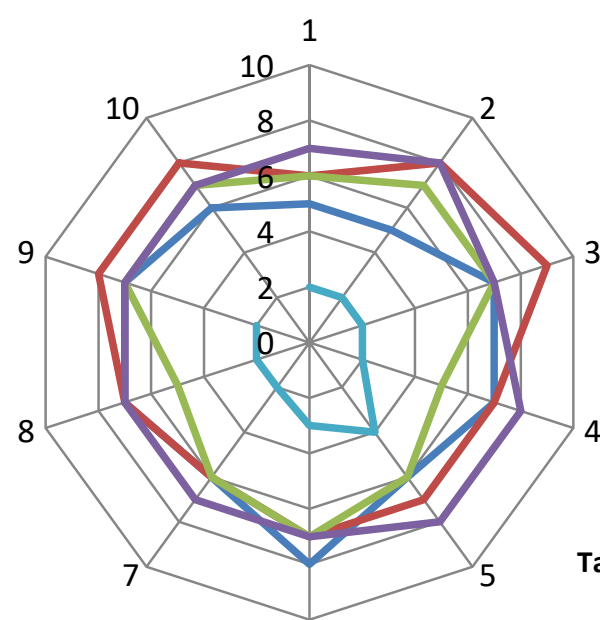

6

(a)

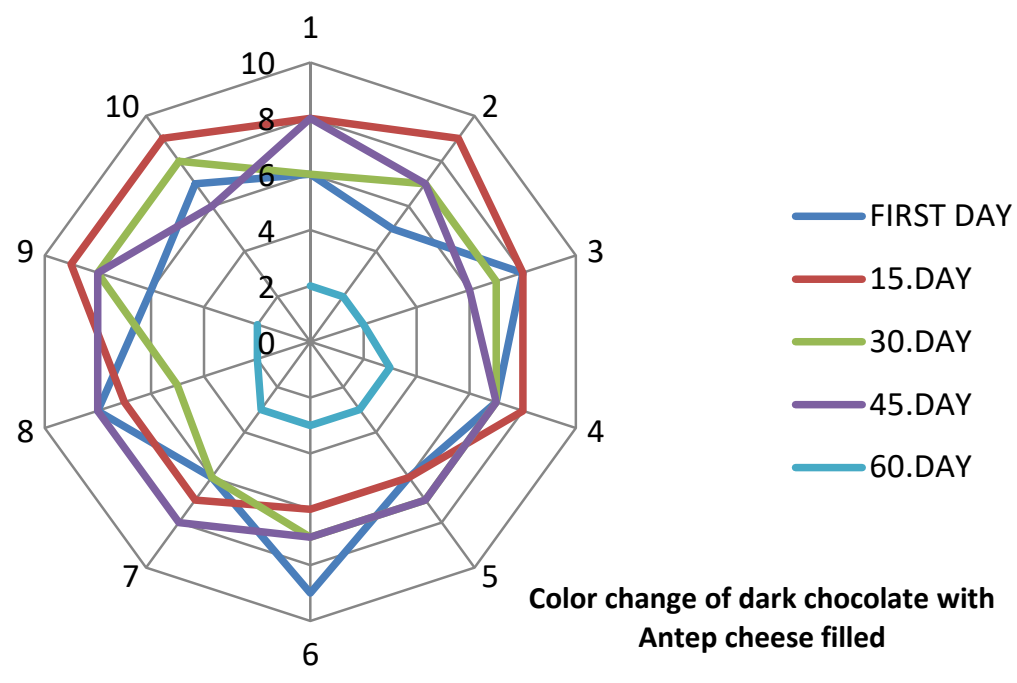

(b)

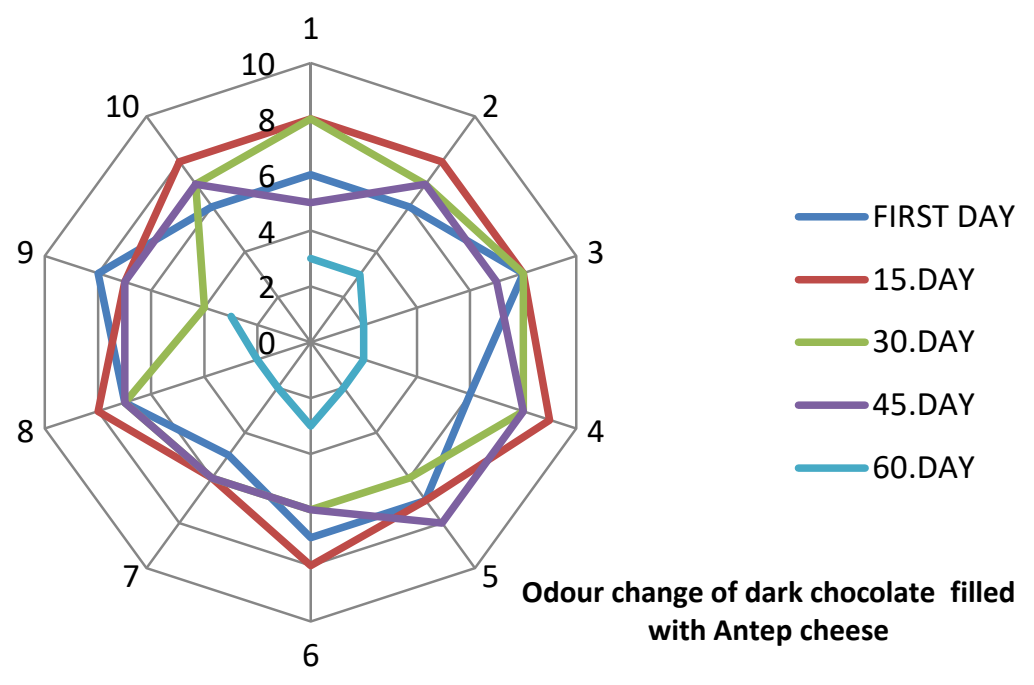

(c) 


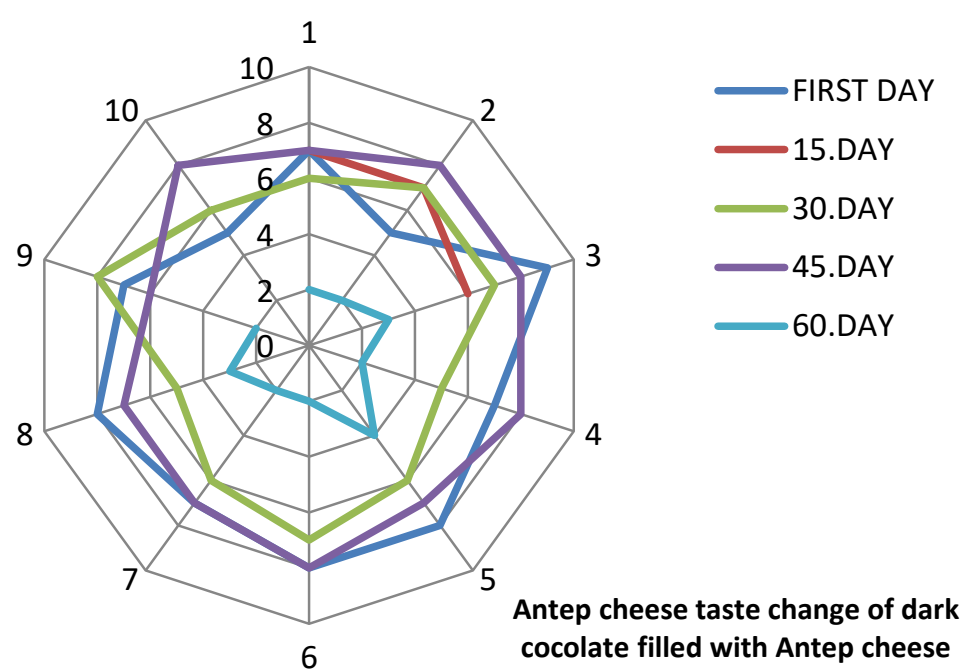

(d)

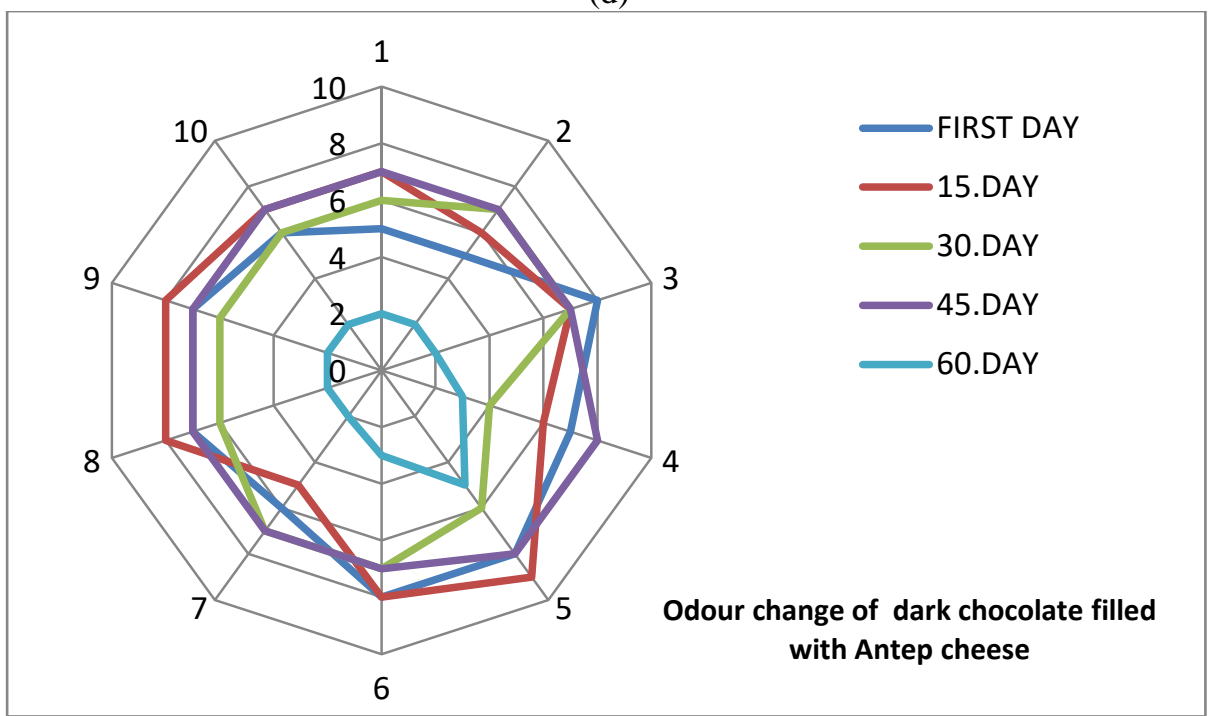

(e)

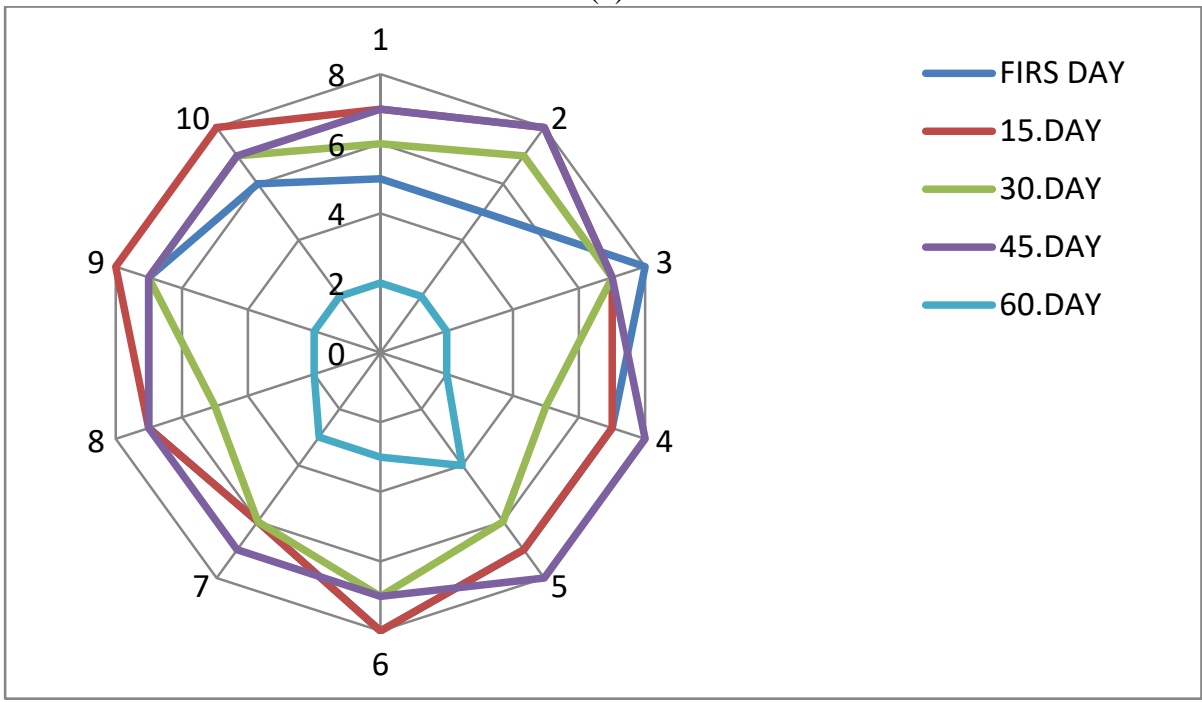

(f)

Figure 3 a,b,c,d,e and f Sensory properties of dark chocolate filled with Antep cheese 50 | P a g e 
It has been seen through the study that Antep cheese does not suppress the taste of the chocolate and it has created a good taste harmony with the chocolate. There was no deterioration between the Antep cheese filling material and the chocolate shell for 75 days. This chocolate has a shelf life of approximately 75 days and is a product that can be found not only in patisserie-style places but also on market shelves.

The results of sensory analysis test were evaluated by one way ANOVA test in SPSS. Tukey test was used for paired multiple comparisons. When the statistical results were examined, it was found that time ( $p>0.05)$ was not an important parameter in general taste, color, odour, Antep pepper taste, Antep pepper odour and general like of bitter chocolate filled with Antep pepper. When Figure 4 was examined, it was observed that the general sensory properties (taste, color and odor) of the dark chocolate with Antep pepper did not change over time. It has been observed that at $18-20{ }^{\circ} \mathrm{C}$, which is the storage temperature of the chocolate, this chocolate can remain unspoiled for approximately 75 days without adding any additives.

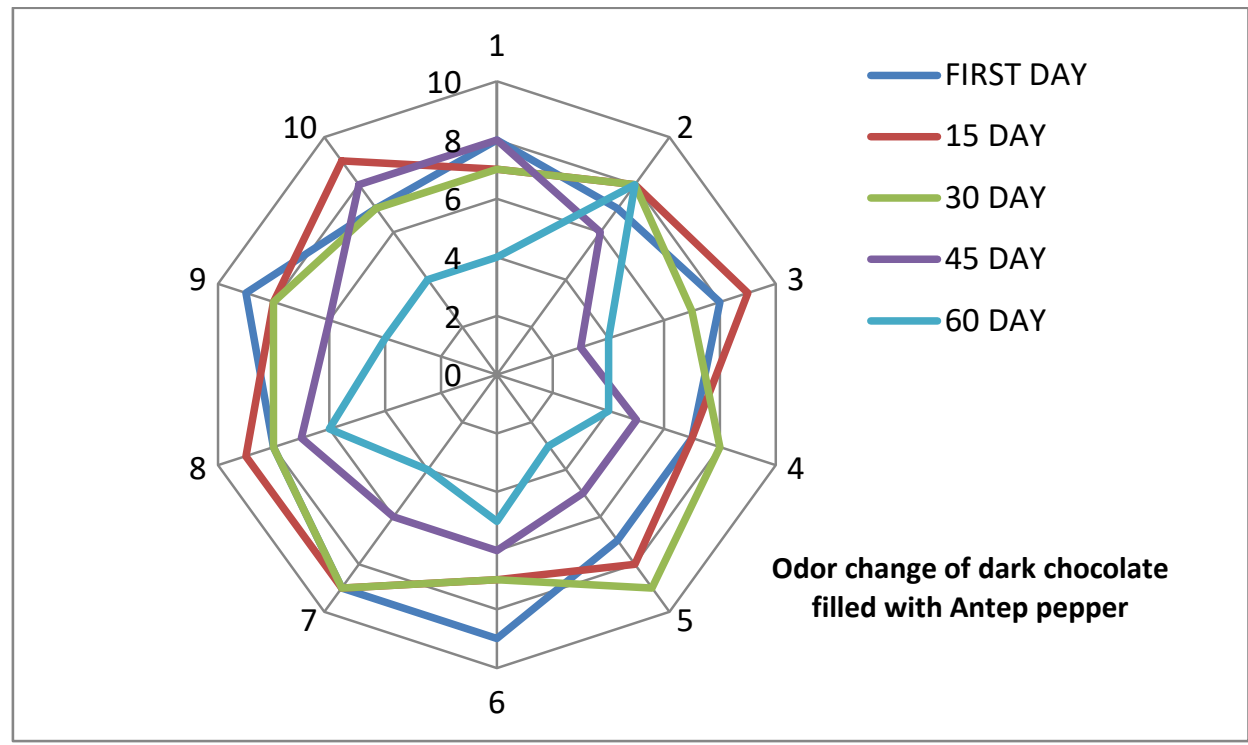

(a)

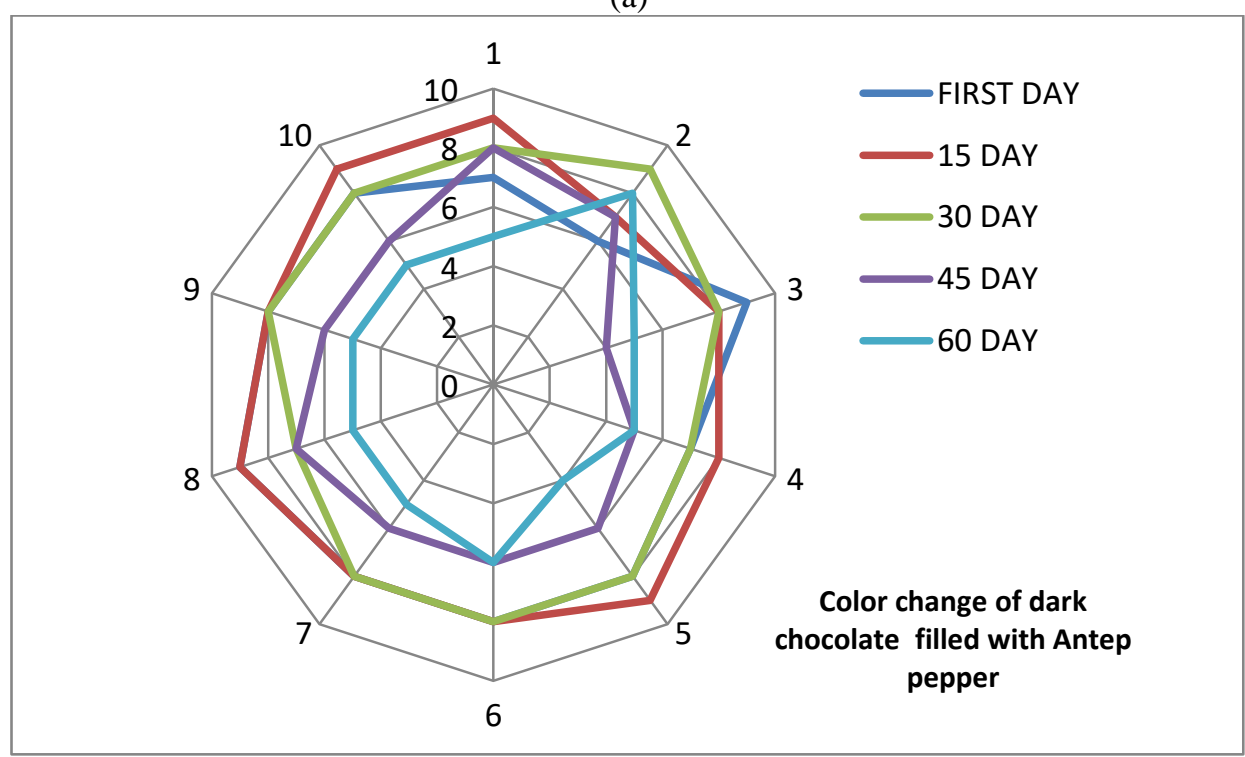

(b) 

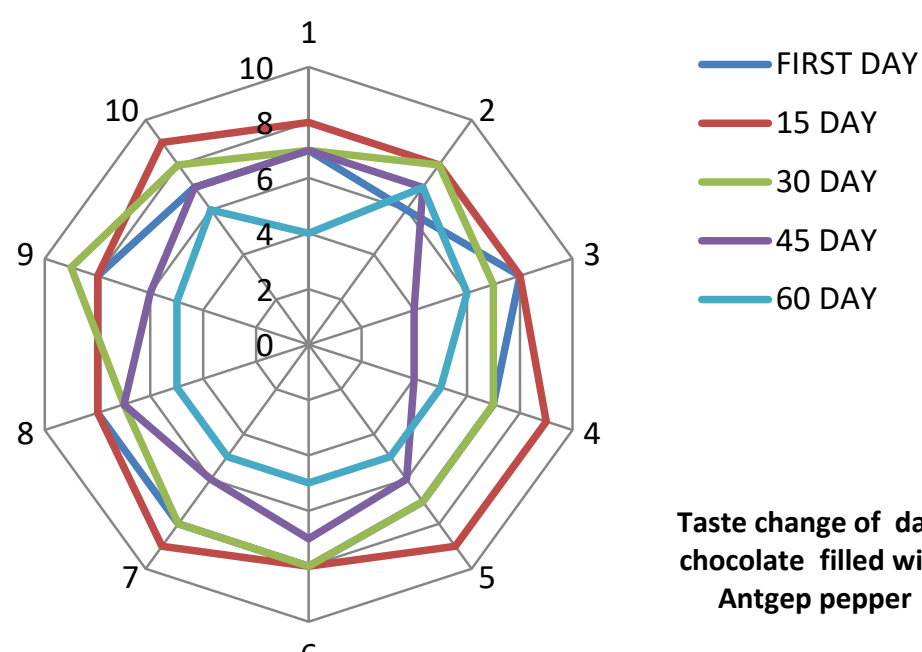

Taste change of dark chocolate filled with

6 Antgep pepper

(c)

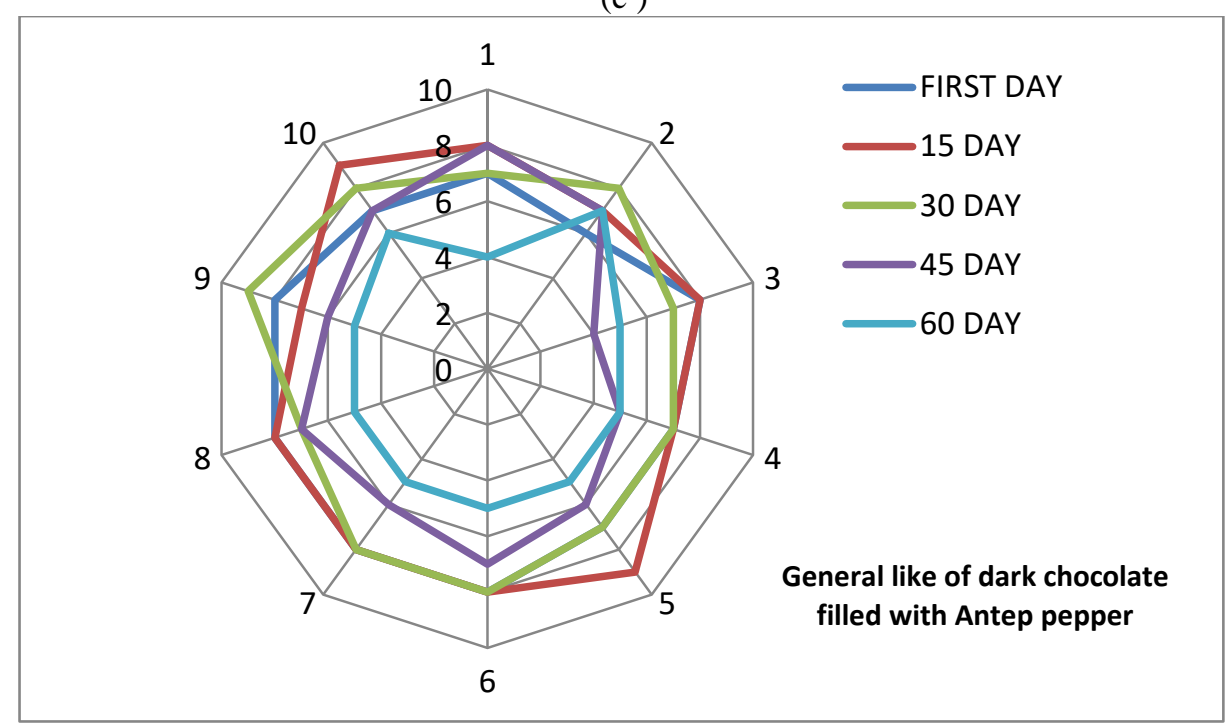

(d)

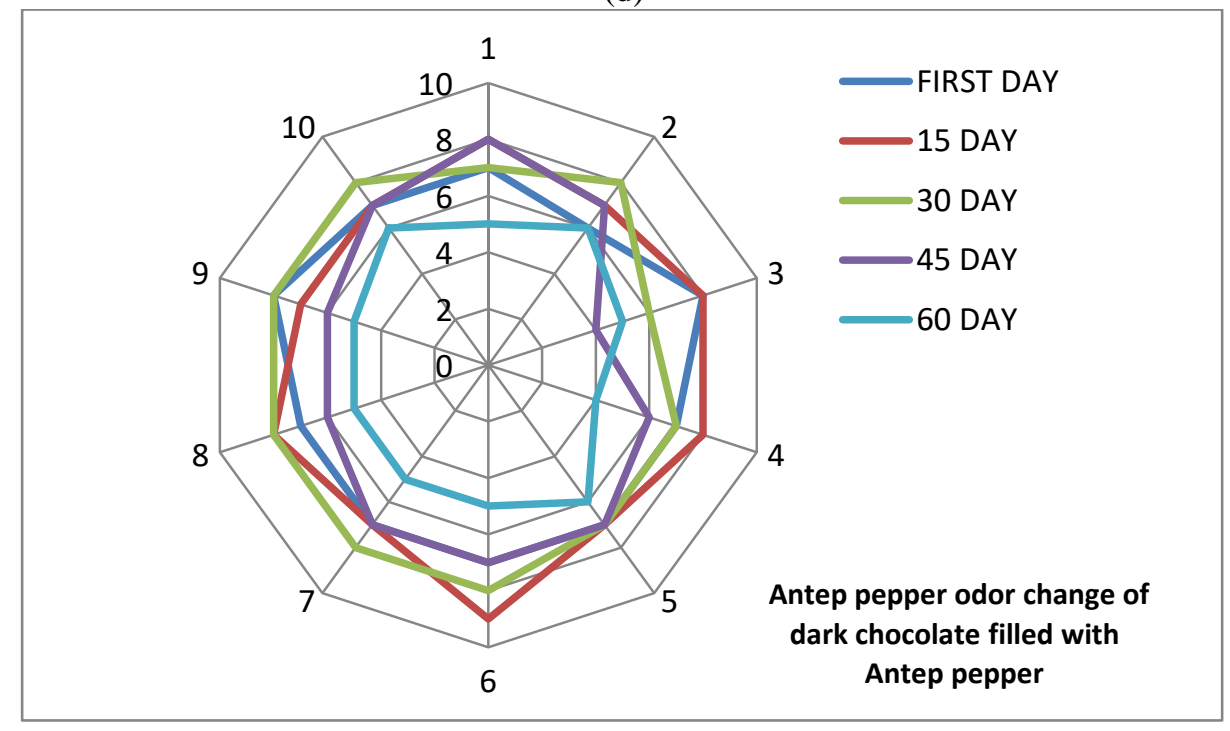

(e )

52 | $P$ a g e

www.iiste.org 


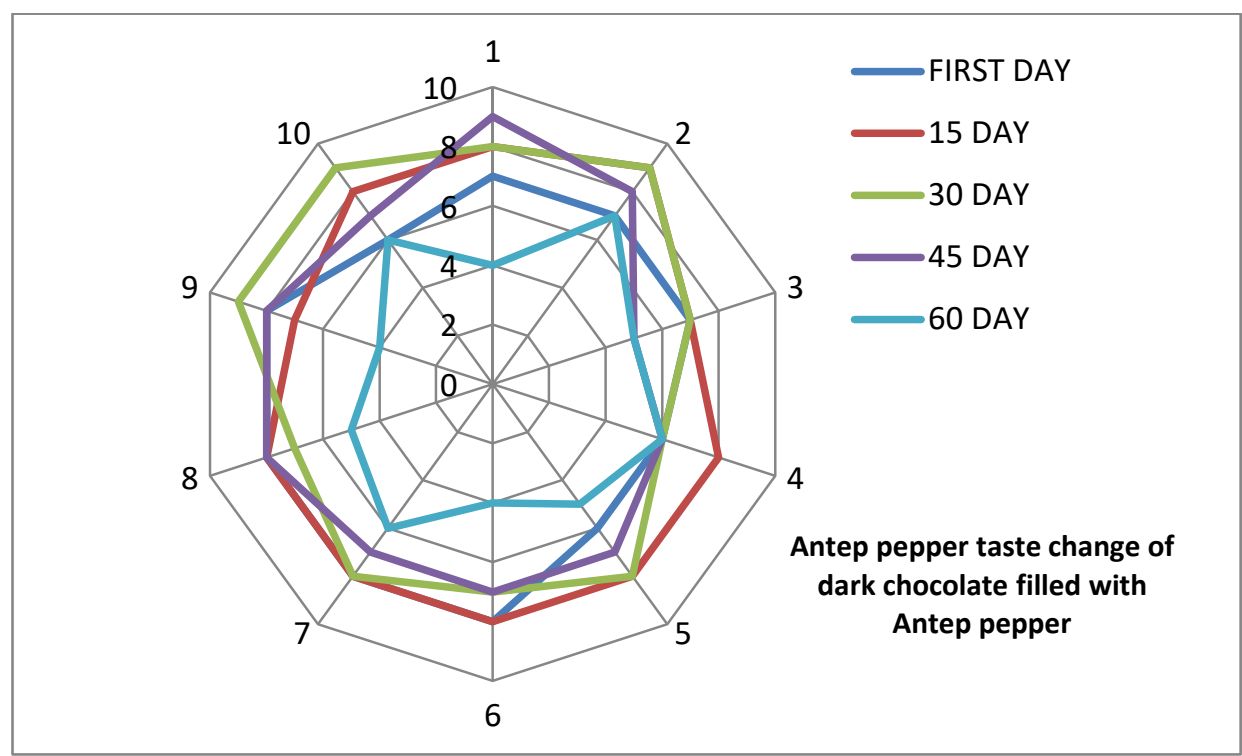

(f)

Figure 4 a,b,c,d,e and f Sensory properties of dark chocolate filled with Antep pepper.

Similar results were obtained for milk and white chocolate filled with Antep pepper. Their graph values are not given. The pepper used in this chocolate is a hot pepper. Its bitter sweet harmony is used in meals in many world cuisines. In chocolate, bitter and sweet taste have achieved a very good harmony. When the results are examined, just like cheese chocolate, pepper chocolate can remain at $18-20^{\circ} \mathrm{C}$ without deterioration for 75 days. This chocolate is a product that can take its place not only in pastry shops but also on market shelves. In addition, when the structure of peppered chocolate was examined sensually, there was no interaction between the chocolate filling material and the chocolate shell, and no sign of any deterioration in its sensory properties.

\section{CONCLUSIONS AND RECOMMENDATIONS}

With this study, two local products of Gaziantep, cheese and pepper, were combined with chocolate, a global product, and two new products were obtained. With the sensory analysis technique, it was tested whether these two new products were an acceptable or unacceptable product and also the shelf life was determined. In the research carried out with the sensory analysis technique, it was concluded that chocolates can remain at $18-20^{\circ} \mathrm{C}$ for 75 days without adding any additives. 2.5 months is an average shelf life for market shelves and therefore this product can be produced in factories and placed on market shelves.

\section{REFERENCES}

www.foofelphi.com www.dergipark.gov.tr www.kulturportali.gov.tr 